\title{
Artemisia Vulgaris L (Tite Paati) a New Source for Immensely Bioactive Compound Naringin
}

\author{
Achyut Adhikari ${ }^{1 *}$ and Salim Saifullah ${ }^{2}$ \\ ${ }^{I}$ Central Department of Chemistry, Tribhuvan University, Kirtipur, Kathmandu, Nepal. \\ ${ }^{2}$ HEJ Research Institute of Chemistry, ICCBS, University of Karachi, Karachi, Pakistan., \\ E-mail:adhikarimine@yahoo.com
}

\begin{abstract}
Naringin, (4',5,7- trihydroxyflavanone-7-rhamnoglucoside), is a flavanone glycoside mainly find in, grapefruits, tomatoes and many other citrus fruits. It has been reported to possess vast biological properties such as antioxidant, anti-inflammatory, atherosclerosis, cardiovascular disorders, diabetes mellitus, neurodegenerative disorders, osteoporosis, rheumatological disorders, antiapoptotic activities, hepatoprotective and chemopreventive effect. Additionally, naringin has anticancer activities in various models of oral, breast, colon, liver, lung, and ovarian cancer. This research work discovered a new natural source for this magic compound, which is plant Artemisia vulgaris L (Tite Paati). Structure of compound was deduced from mass and $1 D$-and $2 D$-NMR techniques. Detail ${ }^{13} C$ - and $2 D$-NMR of compound naringin is also reported in this paper.
\end{abstract}

Keywords: Artemisia vulgaris, naringin

\section{Introduction}

Artemisia is a large genus of plants with between 300 and 500 species of Asteraceae family ${ }^{1}$. A comprehensive inspection of literature exposed that species of Artemisia exhibit a number of biological activities like as antioxidant, antimalarial, antifungal cytotoxic, antibacterial, and antihepatotoxic activity ${ }^{1}$. This genus has been credited for very significant drug artemisinin, a famous anti-malarial drug first time extract from the Chinese aromatic plant Artemisia annиа ${ }^{2}$. Phytoconstituents of this genus are coumarins, caffeoylquinic acids, sterols, acetylenes terpenoids, and flavonoids ${ }^{1}$.

Artemisia vulgaris $\mathrm{L}$ is a persistent wild plant growing natural and in abundance in moderate and frozen temperature areas of the globe. Artemisia vulgaris has been eminent not only as a safe to eat plant but more familiar as a folk medicine supply. ${ }^{3}$ The miscellaneous biological activities of genus Artemisia are manifested by various compounds whose major components are essential oils and flavonoids. ${ }^{1}$

Naringin has shown to possess strong superoxide scavenging and xanthine oxidase inhibitory activity. ${ }^{4,5}$ It suppressed LPS-induced synthesis of NO, iNOS, COX-2, TNF- $\alpha$, IL-6 production, and NF$\kappa \mathrm{B}$ activation in RAW 264.7 macrophages, ${ }^{6}$ and prevents in vitro LDL oxidation and therefore could potentially retard the progression of atherosclerosis. ${ }^{7}$ Naringin showed potent vasorelaxant effect, ${ }^{8}$ and protective effects on the pancreatic islets. ${ }^{9}$ Naringin has also shown dose-dependent protective effects on rotenone-induced cell death in human neuroblastoma SH-SY5Y cells by reducing the activity of caspase-

${ }^{*}$ Corresponding author 


\section{J. Nepal Chem. Soc., Vol. 36, 2017}

3, caspase-9, and PARP, and inhibiting JNK and p38 phosphorylation. ${ }^{10}$ Naringin inhibited PhIP induced genotoxicity in human liver slices, highlighting a protective effect against naturally occurring genotoxins in food such as PhIP and other cooked food mutagens. ${ }^{11}$

Naringin has shown to inhibit the proliferation of human breast carcinoma as well as DMBA-induced mammary tumor formation in female Sprague-Dawley rats. ${ }^{12}$ In A549 human lung cancer cell lines, naringin suppressed the enhancing effect of beta-carotene on DNA damage induced by a potent tobaccorelated carcinogen in humans. ${ }^{13}$ Naringin has been shown to offer significant protection in Nnitrosodiethylamine-induced liver carcinogenesis in rats. ${ }^{14}$ In a hamster cheek pouch model, naringin significantly reduced the tumor burden in DMBA-induced oral cancer. ${ }^{15}$ In an in vitro study on human keratinocytes and fibroblasts, naringin prevented the formation of double strand DNA breaks following exposure to UV radiation. ${ }^{16}$ In rat osteoblast-like UMR-106 cells, naringin increased cell proliferation and ALP activity. ${ }^{17}$ Many more bioactivities of naringin is summarized in review paper by Bharti et. al. ${ }^{18}$.

\section{Experimental and Methods}

\section{General Experimental}

Optical rotations were recorded on a JASCO digital polarimeter (model DIP-3600) in chloroform and methanol. Purity of compound was confirmed using pre-coated silica gel TLC $(20 \times 20,0.5 \mathrm{~mm}$ thick, E. Merck, type 70-230 Mesh), were examined under UV light at 254 and $366 \mathrm{~nm}$. Spots on TLC plates were further confirmed by spraying with ceric sulfate reagent. Jeol MS route JMS $600 \mathrm{H}$ attached with TSS 2000 was used to record EI-MS. The HREI-MS measured on Thermo Finnigan MAT 95XP attached with X-calibur. Jeol JMS-HX 110 attached with TGRAF-4200 mass spectrometer was used for the FAB-MS (Fast Atom Bombardment Mass Spectrum) and HRFAB-MS (High Resolution Fast Atom Bombardment). The IR spectra were acquired from FTIR-8900 (Fourier Transform Infrared Spectrophotometer, Shimadzu, Japan) using $\mathrm{KBr}$ disc. UV/Visible spectra were acquired from Evolution UV-Visible spectrophotometer (Thermoscientific, United State) in $\lambda_{\max }(\varepsilon)$. Polarimeter P-2000 (JASCO, Japan) was used to measure optical rotations. All 1D- and 2D- NMR spectra were recorded on Avance 300, 400 and $500 \mathrm{MHz}$ instruments.

\section{Plant Material}

The plant was collected from Kathmandu Nepal, during Aug, 2015. The plant material was identified by Prof. Dr. Krishna Kumar Shrestha Central Department of Botany, Tribhuvan University, Kathumandu Nepal.

\section{Extraction and Isolation}

$2.75 \mathrm{Kg}$ air dried plant material is grinded or cut into small pieces to make homogenous powder and macerated (ratio $1 \mathrm{~g} / 10 \mathrm{~mL}$ ) in methanol. $250 \mathrm{~g}$ methanolic extract received after evaporation of solvent. It was dissolved in distilled water and preceded for fractionation. The Ethyl acetate fraction was impelled to the silica gel column, flushed with different grade of hexane, ethyl acetate, and acetone, which given a number of sub-fractions EA, EB, EC, ED, and EE. Sub-fraction EA was further passed through silica gel column, eluted with 50\% acetone in hexane. Fraction EB was chromatographed on silica gel column flushed with ethyl acetate and hexane (8:2) and collected to sub-fractions EBa and $\mathbf{E B b}$. Fraction EBb was eluted on LH-20 sephadex column using methanol as mobile phase afford compound $\mathbf{1}$ (30.0 mg). 


\section{Results and Discussion}

Compound 1 was obtained as a dirty white amorphous solid from ethyl acetate fraction. The EI-MS spectrum of compound 1 showed the $\left[\mathrm{M}^{+}\right]$at $m / z 580$ and base peak at $m / z 272$. The ${ }^{1} \mathrm{H}-\mathrm{NMR}$ spectrum (Table-1) showed resonances for four signals at $\delta 5.37 \mathrm{dt}\left(J_{2,3 \mathrm{a}}=12.8, J_{2,3 \mathrm{~b}}=4.7 \mathrm{~Hz}\right), 2.74 \mathrm{~d}\left(J_{3,2}=12.8\right.$ $\mathrm{Hz}), 6.16 \mathrm{~d}\left(J_{6,8}=2.2 \mathrm{~Hz}\right)$, and $6.16 \mathrm{~d}\left(J_{8,6}=2.0 \mathrm{~Hz}\right)$ were assigned to $\mathrm{H}-2, \mathrm{H}-3, \mathrm{H}-6$, and H-8 respectively. Signals resonated at $\delta 7.32 \mathrm{~d}\left(J_{2},{ }_{3},=8.5 \mathrm{~Hz}\right), 6.80 \mathrm{dd}\left(J_{3},{ }_{2},=8.5 \mathrm{~Hz}, J_{3},{ }_{5},=1.8 \mathrm{~Hz}\right), 6.80$ $\mathrm{dd}\left(J_{5}, 6^{\prime}=8.5, J_{5}, 3^{\prime}=1.8 \mathrm{~Hz}\right)$, and $7.32 \mathrm{~d}\left(J_{6}, 5^{\prime},=8.5 \mathrm{~Hz}\right)$ were due to protons attached to H-2', $\mathrm{H}^{\prime} 3^{\prime}, \mathrm{H}^{-}$ 5', and H-6' respectively. Signal resonated at $\delta 5.08 \mathrm{~d}\left(J_{1},, 2^{\prime},=8.5 \mathrm{~Hz}\right)$ and $5.23 \mathrm{~d}\left(J_{1}, ", 2^{\prime},=5.2 \mathrm{~Hz}\right)$ were attributed to anomeric protons attached to anomeric carbons C-1"' and C-1',' respectively. An up field signal resonated at $\delta 1.3$, was attributed to protons of C-6",'. The existence of methyl signal in sugar moiety confirmed the rhamnose moiety in compound.

The broad band ${ }^{13} \mathrm{C}-\mathrm{NMR}$ and DEPT spectra (Table-1) revealed resonance for twenty seven carbons, including one methyl, two methylene, seventeen methines, and seven quaternary carbons. 2D NMR spectroscopy (COSY, NOESY, HSQC, and HMBC) (Fig-1) were brought in use to predict the position of sugar moiety and conforming the compound 1 structure. The HMBC interaction between anomeric proton and carbons resonated at $\delta 5.08$ and $\delta 166.3$ (C-7), clearly showed the location of sugar moiety in compound. The HMBC interaction of protons methyl group of rhamnose with anomeric carbon, and the interaction of anomeric proton of rhamnose to glucose moiety clearly showed the position of both moieties in compound.

Table-1: ${ }^{13} \mathrm{C}$ - and ${ }^{1} \mathrm{H}-\mathrm{NMR}$ chemical shift values of 1 (MeOD, ppm, 125 and $500 \mathrm{Mhz}$ )

\begin{tabular}{|l|l|l|l|l|l|}
\hline C. No. & $\delta_{\mathrm{C}}$ & $\delta_{\mathrm{H}}(\mathrm{J}, \mathrm{Hz})$ & C. No. & $\delta_{\mathrm{C}}$ & $\delta_{\mathrm{H}}(\mathrm{J}, \mathrm{Hz})$ \\
\hline 2 & 80.8 & $5.37 \mathrm{dt}(12.8,4.7)$ & $1^{\prime \prime}$ & 99.4 & $5.08 \mathrm{~d}(8.5)$ \\
3 & 44.2 & $2.74 \mathrm{~d}(12.8)$ & $2^{\prime \prime}$ & 79.14 & 3.64 ovp \\
4 & 198.5 & - & $3^{\prime \prime}$ & 72.2 & 3.59 ovp \\
5 & 165.5 & - & $4^{\prime \prime}$ & 71.3 & 3.39 ovp \\
6 & 98.2 & $6.16 \mathrm{~d}(2.2)$ & $5^{\prime \prime}$ & 78.4 & 3.45 ovp \\
7 & 166.3 & - & $6^{\prime \prime}$ & 62.1 & 3.67 ovp \\
8 & 97.3 & $6.16 \mathrm{~d}(2.2)$ & $1^{\prime \prime \prime}$ & 102.7 & $5.23 \mathrm{~d}(5.2)$ \\
9 & 165.6 & - & $2^{\prime \prime \prime}$ & 74.1 & 3.38 ovp \\
10 & 106.1 & - & $3^{\prime \prime \prime}$ & 72.0 & 3.93 ovp \\
$1^{\prime}$ & 129.8 & - & $4^{\prime \prime \prime}$ & 70.0 & 3.87 ovp \\
$2^{\prime}$ & 128.7 & $7.32 \mathrm{~d}(8.5)$ & $5^{\prime \prime \prime}$ & 72.3 & 3.59 ovp \\
$3^{\prime}$ & 116.1 & $6.8 \mathrm{dd}(8.5,1.8)$ & $6^{\prime \prime \prime}$ & 18.8 & $1.3 \mathrm{~s}$ \\
$4^{\prime}$ & 159.4 & - & & & \\
$5^{\prime}$ & 116.1 & $6.8 \mathrm{dd}(8.5,1.8)$ & & & \\
$6^{\prime}$ & 128.7 & $7.32 \mathrm{~d}(8.5)$ & & & \\
\hline
\end{tabular}




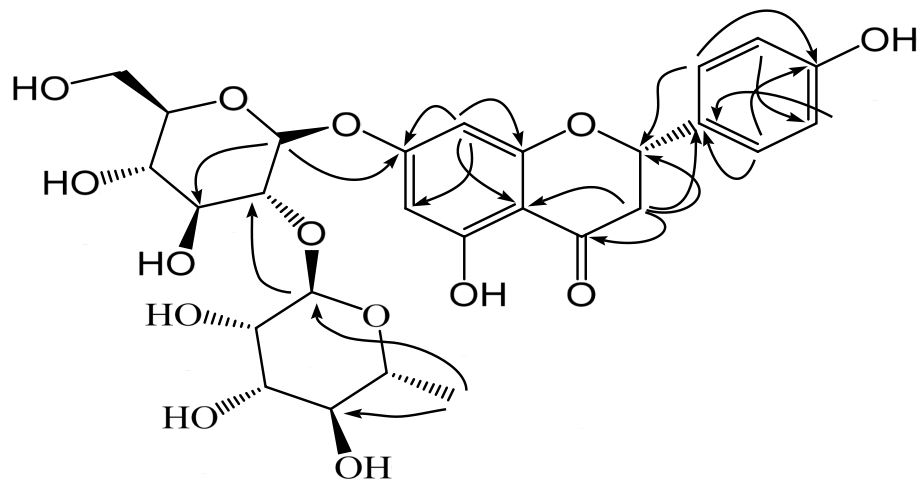

Fig-1: Key HMBC interactions of 1

\section{Conclusion}

Artemisia vulgaris (Tite pati) from Nepal contains widely bioactive compound naringin, therefore the plant Artemisia vulgaris can be a natural raw material for many herbal formulations to cure diseases.

\section{Acknowledgement}

We would like to thank Dr Khaga Raj Sharma, Central Department Central Department of Chemistry, Tribhuvan University for helping in the collection of plant.

\section{References}

1. I. Karabegović, N. Milena, D. Veličković, S. Stojičević, V. Veljković, and M. Lazić, Chin. J. Chem. Eng. 2011, 19(3), 504-511.

2. N. J. White, Antimicrob. Agents Chemother. 1997, 41(7), 1413-1422.

3. S.- J. Lee, H.-Y. Chung, G. A. Camelia, A. R. Wood, R. A. Dixon, and T. J. Mabry. J. Agric. Food Chem. 1998, 46 (8), 3325-3329.

4. Y. T. Chen, R. L. Zheng, Z. J. Jia, and Y. Ju, Free Radic. Biol. Med. 1990, 9, 19-21.

5. A. Russo, R. Acquaviva, A. Campisi, V. Sorrenti, C. DiGiacomo, G. Virgata, M. L. Barcellona, and A. Vanella, Cell Biol. Toxicol. 2000, 16, 91-98.

6. S. Kanno, A. Shouji, A. Tomizawa, T. Hiura, Y. Osanai, M. Ujibe, Y. Obara, N. Nakahata, and M. Ishikawa, Life Sci. 2006, 78, 673-681.

7. G. A. Naderi, S. Asgary, N. S. Zadegan, and H. Shirvany, Mol. Cell Biochem. 2003, 246, $193-$ 196.

8. M. Ajay, A. U. Gilani, and M. R. Mustafa, Life Sci. 2003, 74, 603-612.

9. H. S. Parmar, P. Jain, D. S. Chauhan, M. K. Bhinchar, V. Munjal, M. Yusuf, K. Choube, A. Tawani, V. Tiwari, E. Manivannan, and A. Kumar, Diabetes Res. Clin. Pract. 2012, 97, 105111.

10. H. J. Kim, J. Y. Song, H. J. Park, H. K. Park, D. H. Yun, and J. H. Chung, Korean J. Physiol. Pharmacol. 2009, 13, 281-285.

11. B. G. Lake, J. A. Beamand, J. M. Tredger, P. T. Barton, A. B. Renwick, and R. J. Price, Mutat. Res. 1999, 440, 91-100. 
12. F. V. So, N. Guthrie, A. F. Chambers, M. Moussa, and K. K. Carroll, Nutr. Cancer, 1996, 26, 167-181.

13. S. L. Yeh, W. Y. Wang, C. S. Huang, and M. L. Hu, Chem. Biol. Interact. 2006, 160, 175-182.

14. T. Prabu, M. Ragunath, and V. Manju, Biomed. Prev. Nutr. 2012, 2, 193-202.

15. E. G. Miller, J. J. Peacock, T. C. Bourland, S. E. Taylor, J. M. Wright, B. S Patil, and E. G. Miller, Nutr. Cancer, 2008, 60, 69-74.

16. R. Greinert, B. Volkmer, S. Henning, E. W. Breitbart, K. O. Greulich, M. C. Cardoso, and A. Rapp, Nucleic Acids Res. 2012, 40(10), 263-10 273.

17. W. Y. Pang, X. L. Wang, S. K. Mok, W. P. Lai, H. K. Chow, P. C. Leung, X. S. Yao, and M. S. Wong, Br. J. Pharmacol. 2010, 159, 1693-1703.

18. S. Bharti, N. Rani, B. Krishnamurthy, and D. S. Arya, Planta medica, 2014, 80 (6), 437-451. 